\title{
Atravessamentos discursivos entre ONGs, empresas, grupos sociais e ativistas, na perspectiva da teoria ator-rede
}

Discursive crosses among NGOs, companies, social groups and activists, from the perspective of actor-network theory

Atravesamientos discursivos entre ONGs, empresas, grupos sociales y activistas, en la perspectiva de la teoría actor-red

\section{Vanessa Cardozo Brandão}

- Doutora em Estudos da Literatura pela Universidade Federal Fluminense (UFF)

- Mestre em Literaturas de Língua Portuguesa pela Pontifícia Universidade Católica de Minas Gerais (PUC Minas)

- Graduada em Publicidade e Propaganda pela Universidade Federal de Minas Gerais (UFMG)

- Professora Adjunta do Departamento de Comunicação Social da UFMG

- Integrante do Núcleo de Pesquisa em Conexões Intermidiáticas (NucCon/CCNM) - CNPq/UFMG

- E-mail: vcbrandao@ufmg.br 


\section{Resumo}

Perpassando a atuação da ONU Mulheres Brasil, observa-se a criação de associações entre organizações vistas como atores interagindo em fluxos intermídias estabelecidos com base na temática da igualdade de gênero, tomada como mediadora das ações comunicacionais em rede sociotécnica. Com a contribuição da teoria ator-rede (Bruno Latour), a cartografia das associações pode revelar como processos de midiatização na web criam interações que contribuem para o estudo de fenômenos de comunicação organizacional, cujas relações podem passar a ser lidas em fluxo.

PALAVRAS-CHAVE: TEORIA ATOR-REDE • SOCIOLOGIA DAS ASSOCIAÇÕES • REDE INTERORGANIZACIONAL・ATRAVESSAMENTOS DISCURSIVOS • IGUALDADE DE GÊNERO.

\section{Abstract}

Analyzing the activities of the ONU Mulheres Brasil, we observe the creation of associations across organizations seen as actors interacting in intermedia flows established based on the theme of gender equality, considered as a mediator of the communication actions in a sociotechnical network. With the contribution of actor-network theory (Bruno Latour), cartography of associations can reveal how processes of web-media exposure create interactions that contribute to the study of organizational communication phenomena, which relations can be read in flow.

KEYWORDS: ACTOR-NETWORK THEORY • SOCIOLOGY OF THE ASSOCIATIONS •INTER-ORGANIZATIONAL NETWORK• DISCURSIVE CROSSES• GENDER EQUALITY.

\section{Resumen}

Al pasar la actuación de la ONU Mujeres Brasil, se observa la creación de asociaciones entre organizaciones vistas como actores interactuando en flujos intermedios establecidos con base en la temática de la igualdad de género, tomada como mediadora de las acciones comunicacionales en red socio-técnica. Con la contribución de la teoría actor-red (Bruno Latour), la cartografía de las asociaciones puede revelar cómo procesos de mediatización en la web crean interacciones que contribuyen al estudio de fenómenos de comunicación organizacional, cuyas relaciones pueden pasar a ser leídas en flujo.

PALABRAS CLAVES: TEORÍA ACTOR-RED • SOCIOLOGÍA DE LAS ASOCIACIONES • RED INTERORGANIZACIONAL • ATRAVESAMIENTOS DISCURSIVOS • IGUALDAD DE GÉNERO. 
ANO 14 • NÚMERO 26 • 10 SEM. 2017 • ORGANICOM

ATRAVESSAMENTOS DISCURSIVOS ENTRE ONGS, EMPRESAS, GRUPOS SOCIAIS E ATIVISTAS, NA

PERSPECTIVA DA TEORIA ATOR-REDE

questão da igualdade de gênero configura-se como um dos principais pontos de interesse público desta última década.
Pautada, muitas vezes, pelo ativismo da própria sociedade, intensificado em processos de comunicação digital, 0
fenômeno parece ser ilustrativo de como os conceitos de midiatização e mediação se tornaram operadores potentes para a compreensão de objetos comunicacionais contemporâneos. Em torno da temática de interesse público, vários processos de comunicação em rede têm se estabelecido em meios digitais e no mundo físico, superando aqui uma dualidade entre essas dinâmicas, pois esses fenômenos há muito se acoplaram em processos de mútua afetação (Santaella, 2016).

Muitas vezes, processos comunicacionais que se desdobram sobre o empoderamento feminino na esfera pública aparecem em discursos organizacionais, atravessados por diversas dimensões, como a do ativismo, do engajamento político, da cidadania e ainda do consumo, como veremos no caso relatado neste artigo.

Esse é um entre outros fenômenos de natureza complexa que têm evidenciado os limites das metodologias de análise de discurso restrita aos âmbitos institucionais das organizações, que tendem a reduzir o fenômeno a um objeto comunicacional, normalmente de caráter institucional e centrado na fala da organização (mesmo que em plataformas interativas), enquanto fonte geradora de produção de sentidos a ser analisado e compreendido. 0 enfoque restrito à organização, tomada como o centro de uma rede de relações com diversos públicos - e uma consequente compreensão do profissional de relações públicas como o gestor ou ainda ordenador dessa rede de relações -, parece ter sido o alvo de grande parte das críticas dirigidas ao campo de comunicação organizacional nas pesquisas desenvolvidas nas últimas décadas.

Nesse sentido é que o presente artigo se propõe trazer os fundamentos teóricos da perspectiva da teoria ator-rede - TAR (Bruno Latour), relacionando-os ao estado da arte contemporâneo em comunicação organizacional, na tentativa de apontar contribuições que o olhar da TAR pode trazer para a compreensão de um estudo da comunicação enquanto interação entre organizações e públicos. Assim, em uma perspectiva alinhada ao paradigma relacional da comunicação, a TAR poderá ser tomada como modo de apontar para o atravessamento entre as dimensões políticas, institucionais e mercadológicas, que se torna visível pelas múltiplas associações entre organizações em suas interações discursivas, midiatizadas em fluxos circulantes nas redes sociais na internet.

\section{REFERENCIAL TEÓRICO: DA ORGANIZAČÃO ENQUANTO SISTEMA À ORGANIZAÇÃO ENQUANTO ÁTOR-EM-REDE}

Fortemente conectada a uma crítica ao paradigma de comunicação informacional (centrado na mensagem e nos sentidos por ela estabelecidos) e à proposição mais contemporânea de um novo paradigma relacional, uma espécie de alargamento do campo da comunicação organizacional parece estabelecer novas frentes para pesquisa. Esse alargamento parece ter ocorrido em duas frentes, para retomar os próprios termos definidores do campo - tanto na dimensão do conceito de "comunicação", por um lado, quanto na dimensão do conceito de "organizacional", por outro.

Sob o prisma da comunicação, a partir do quadro relacional, pode emergir uma nova visão dos processos comunicacionais enquanto interação entre sujeitos em comunicação (França, 2006), que, como aponta Fábia Lima (2008), pode levar a um avanço nas abordagens analíticas da empiria no contexto das organizações ao levar ao entendimento de "como as organizações constituem um contexto específico de interações, com base no qual o fenômeno da comunicação pode ser analisado, embora não represente a totalidade desse fenômeno" (Lima, 2008, p. 124). 
ANO 14 • NÚMERO 26 • 10 SEM. 2017 • ORGANICOM

ATRAVESSAMENTOS DISCURSIVOS ENTRE ONGS, EMPRESAS, GRUPOS SOCIAIS E ATIVISTAS, NA

PERSPECTIVA DA TEORIA ATOR-REDE

Com relação à dimensão do "organizacional", a partir do paradigma da complexidade, torna-se urgente rever a percepção da organização enquanto sujeito de central importância dentro dos processos de comunicação que a circundam. Nesse sentido, retomamos a proposição de Rudimar Baldissera sobre o paradigma da complexidade de Edgar Morin e seu impacto na própria ontologia da organização, que passa a ser vista como "um ser organizacional, muitas vezes, independentemente da vontade e dos objetivos da própria organização" (Baldissera, 2008, p. 169). Assim, a organização torna-se um ethos cuja identidade não pode ser dada como pronta ou controlada (apenas por sentidos planejados por gestores), mas também ela é uma identidade construída. Em grande parte, essa identidade se constrói através da comunicação, entendida não enquanto uma "enunciação do ser" por parte da organização (através de seus discursos autorizados), mas como um sujeito "afetado" em relações de alteridade, que se desenha enquanto estabelece relações de interação com outros sujeitos.

Dessa perspectiva é que se abre espaço para pensar a comunicação organizacional como campo de relações com outros atores que tecem o ser organizacional, de forma complexa e dinâmica. Interessa-nos salientar que isso se estabelece como um agenciamento entre três dimensões comunicacionais da organização, que serão conceituados assim por Baldissera (2011): organização comunicada, organização comunicante e organização falada. Mais do que aprofundar esses conceitos, neste artigo interessa-nos destacar que eles parecem sinalizar para a ideia de que a comunicação organizacional transcende os processos de comunicação "autorizados" pela organização e, mais ainda, que outros sujeitos são chamados à cena para, em processos de disputa de sentidos, agir sobre as organizações. Os sujeitos não são apenas "públicos de interesse" para uma organização: eles são atores, que agem sobre as organizações tanto quanto "são agidos" por ela, em uma interação que parece tornar evidente uma aproximação com a perspectiva da teoria ator-rede.

Segundo se pretende mostrar, com a contribuição da perspectiva da teoria ator-rede, tomando por base as formulações de Bruno Latour (2012) e o impacto delas sobre uma visão complexa de dinâmicas sociais enquanto processos de associação de atores-em-rede, é possível olhar para a comunicação de organizações de diferentes naturezas - sejam elas ONGs, grupos comunitários ou ativistas, ou empresas - e para suas associações, a partir da compreensão da rede de fluxos e relações das quais fazem parte e que as engendram e conformam, para além do enfoque estrito nos interesses de uma organização com seus diversos stakeholders.

No cenário da midiatização, o controle e a vigilância dos públicos pela ação de "radar" da comunicação organizacional parece cada vez mais incabível, em especial porque o universo não é 0 "da" organização fechada em si mesma, mas o de uma multiplicidade de elos configurados a partir do olhar sobre a organização, ou mesmo através dela, como apontado por Antônio Fausto Neto (2008, p. 55):

Afinal de contas, uma determinada organização não é, hoje, um universo fechado e monotemático, na medida em que está atravessada por fragmentos e injunções de multitemas e de problemas e diferentes campos sociais, e, a seu turno, sempre em processos de disputas de pontos de vista. (...) Projetando estas questões sobre a vida das organizações, pode-se dizer que estas se constituem, em meio à multiplicidade de agendas, objeto de transações relacionais e múltiplas, umas com as outras, pondo em jogo suas diferenças e multiplicidades.

Tal perspectiva do pesquisador sobre a indeterminação de sentido nos processos comunicacionais e o descontrole de uma organização sobre eles, em grande parte deriva da sua compreensão do cenário de midiatização. Como vista por Fausto Neto, a midiatização enquanto ambiência (com semelhanças ao conceito de bios midiático de Muniz Sodré) torna-se mais do que "entorno" para as ações das organizações e dos sujeitos. Ela gera "uma nova forma de vida, e a própria noção contemporânea de esfera pública afeta(m) o modo de ser das instituições, na medida em que suas "leis" se inscrevem nos diferentes campos sociais ou são tomadas como referencias por suas estratégias" (Fausto Neto, 2008, p. 57). Mais do que apenas a profusão 
generalizada de meios para organizar a interação dos campos diversos do social, a midiatização corresponde a uma nova configuração do social que se constitui em operações múltiplas de campos sociais que tem nas mídias "uma das condições de produção dos discursos que promoverão sua visibilidade e, consequentemente, sua legitimidade" (Fausto Neto, 2008, p. 57). Apontando nessa direção é que Fausto Neto parece sinalizar para outro lugar da comunicação organizacional que possa ser visto como uma "pragmática comunicacional", para além da metáfora de um "radar" normalmente associada ao campo, mas que contemple a escuta dos sujeitos em comunicação feita de um modo diferente, a partir "das indeterminações dos atores em situações de interação" (Fausto Neto, 2008, p. 60).

Vista desse modo, pela perspectiva da impossibilidade do controle do agenciamento de sentidos no ambiente de fluxos, parece-nos possível, ou mesmo desejável, relacionar o conceito de midiatização e uma nova concepção da dinâmica mídia/ sociedade (com impactos sobre o campo de estudos da comunicação organizacional), à perspectiva da TAR sobre uma sociologia das associações de Bruno Latour (2012). De partida, é importante contextualizar o pensamento do sociólogo, tratado em profundidade em Reagregando o social: Latour renova o modo de ver a sociologia, sugerindo passar de uma abordagem do "social" enquanto dimensão (uma entre outras, como a cultural, a política, a legal) para outra em que o social é tomado como a própria dinâmica de organização, resultante da associação entre atores.

Neste trabalho, a contribuição da teoria ator-rede será inspiradora de um gesto epistemológico e metodológico: a concepção das organizações vistas sob o prisma de ator-rede. 0 termo, na TAR, é importante para compreensão do modo de ver da sociologia das associações. Entendendo a relação entre atores (ou actantes'1, tal como o termo usado na teoria para abarcar uma visão complexa de rede que ultrapasse a noção de que apenas atores humanos façam parte ou possam agir na rede) e rede de modo imbricado, a TAR difere do pensamento de rede enquanto um sistema maior que engloba atores, vistos como nós ou partes menores de uma rede. Na verdade, o que o hífen entre ator-rede sinaliza é exatamente uma junção tal entre atores e rede de modo que um actante (humano ou não humano) possa ser tomado como ponto de leitura da rede, que deixa de ser mais do que a soma de vários atores em pontos interconectados a serem explicados, ou compreendidos e analisados em um todo coeso. De fato, na perspectiva da TAR, rede é um conceito que está diretamente ligado às associações ocorridas na dinâmica social, como afirma André Lemos (2013, p. 53):

Rede, para a TAR, não é infraestrutura, mas o que é produzido na relação entre humanos e não-humanos. Não estamos falando de redes de computadores, de redes sociais, de redes de esgoto... Rede é aqui um conceito dinâmico. Não é o que conecta, mas o que é gerado pelas associações. Não é algo pronto, por onde coisas passam, mas o que é produzido pela associação ou composição de atores humanos e não-humanos. Rede não é estrutura, mas o que é tecido em dada associação. Quando falamos de rede, estamos falando de mobilidade. Ao olharmos o mundo, vemos redes se fazendo e se desfazendo a todo momento. 0 conceito de rede visa apreender algo pulsante, o que se forma e se deforma aqui e acolá pela dinâmica das relações.

Daí a importância da cartografia como método para compreender o social: se um ator é parte que age, e também é agidoem rede, a melhor forma de compreender a interação em rede não poderia enfocar apenas um ator e seu poder de agência, mas antes poderia ser vista a partir do mapeamento de fluxos de associação de atores em torno de uma determinada dinâmica social. Essa concepção parece ser particularmente rica e produtiva para se pensar o modo como as organizações têm formado/feito parte de associações dentro da rede - ou redes interorganizacionais, como iremos propor neste trabalho -, de forma a ganharem alcance e visibilidade, aproveitando o modo como os algoritmos das mídias sociais na internet (actante

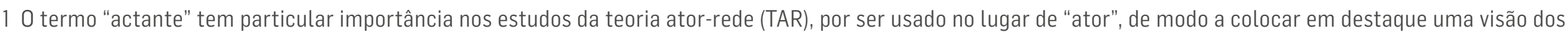

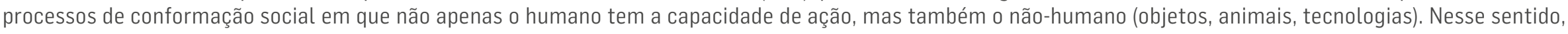

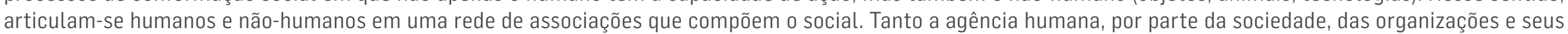

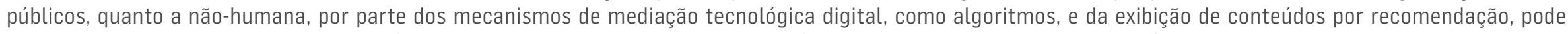
passar a ser considerada no escopo da análise de interações em rede, dentro do princípio de simetria dos actantes, um dos fundadores da concepção da TAR. 
ANO 14 • NÚMERO 26 • 10 SEM. $2017 \cdot$ ORGANICOM

ATRAVESSAMENTOS DISCURSIVOS ENTRE ONGS, EMPRESAS, GRUPOS SOCIAIS E ATIVISTAS, NA

PERSPECTIVA DA TEORIA ATOR-REDE

tecnológico) tendem a tornar ainda mais visível uma organização para uma pessoa a partir da oferta de conteúdos similares ao que a pessoa já consome - elemento de particular importância na atração de um número crescente de empresas que têm se associado à pauta do gênero como modo de serem "carregadas" nos fluxos de interação social na web.

Com frequência, entretanto, o engajamento em redes formadas no ambiente digital tem acontecido com as temáticas de interesse público, com desdobramentos políticos e de ativismo social. Debates sobre questões culturais relevantes, como a equidade social e o empoderamento feminino, reverberam com a formação de comunidades politicamente engajadas, criando circuitos em que processos de mediação sociocultural ganham ampla visibilidade em processos de midiatização em rede.

A proposta da TAR, então, pode trazer um olhar produtivo sobre a leitura da atuação discursiva de organizações. Ela enseja um movimento de observação que nos parece mais coerente com o estudo de fluxos comunicacionais em rede. Afinal, ao procurar monitorar tendências de fluxos discursivos em rede para se colocar como parte dessa temática midiatizada pela sociedade, a organização já demonstra compreender que faz parte de um processo de interações de sentido que a transcende, e dentro do qual pretende se inserir, por associação. Portanto, mais do que analisar, com categorias levantadas a priori, uma organização como um objeto de estudo na rede partindo de sua centralidade do processo comunicacional, pode-se ampliar o escopo dos estudos ao se enfocar na análise das interações entre diferentes organizações enquanto atores de uma rede, tomando uma dessas organizações apenas como impulso inicial de observação de uma dinâmica social mais ampla.

O material empírico escolhido para ensaio torna-se emblemático, nesse sentido, porque congrega organizações de natureza diversa: organização intergovernamental, empresas, organizações não-governamentais e grupos ativistas. A partir da agenda da igualdade de gênero, esses atores se articulam em rede, dando a ver um complexo atravessamento discursivo em que o empoderamento feminino se transforma no elo mediador de fluxo midiatizado entre mídias digitais, carregando dimensões distintas (e por vezes conflitantes) como as políticas, educativas, institucionais e mercadológicas.

\section{TAR: UMA TEORIA E UM MÉTODO}

O trabalho analítico a seguir parte da concepção da sociologia das associações da teoria ator-rede (TAR) para reconhecer uma rede de associações que se desvelou, como objeto de análise, a partir da atuação em redes sociais da ONU Mulheres Entidade das Nações Unidas para a Igualdade de Gênero e o Empoderamento das Mulheres, criada em 2010 para congregar todas as ações desenvolvidas pela ONU para a transformação social da situação de desigualdade de direitos entre mulheres e homens - uma questão de dimensão global.

Embora a observação do levantamento empírico tenha partido, inicialmente, de discursos produzidos e compartilhados pela organização em sua página brasileira no Facebook, a ONU Mulheres Brasil, no gesto de pesquisa aqui empenhado, as postagens oficiais de ONU Mulheres são tomadas como vestígio material de um agenciamento maior em rede de associação de diferentes atores. Com base nele, torna-se necessário mapear e seguir os actantes, de modo a compreender a realidade de diferentes atores-organizações que se associam em torno da temática de igualdade de gênero, durante um período temporal marcado pelo acontecimento midiatizado "Dia Internacional da Mulher", em março de 2017. Assim, coloca-se como proposição central da pesquisa o ato de mapear e observar as interações em rede, tendo como gesto metodológico 0 olhar que, a partir de uma organização e de seus discursos na internet, busca revelar uma rede maior de atores associados, desencadeando um fluxo de interações com outras ONGs, empresas e mesmo ativistas do feminismo. 
ANO 14 • NÚMERO 26 • 10 SEM. 2017 • ORGANICOM

ATRAVESSAMENTOS DISCURSIVOS ENTRE ONGS, EMPRESAS, GRUPOS SOCIAIS E ATIVISTAS, NA PERSPECTIVA DA TEORIA ATOR-REDE

A pesquisa se inicia de um lugar, que é uma organização intergovernamental e do discurso de igualdade de gênero e empoderamento feminino por ela proposto, mas a ONU Mulheres não deve ser vista como o centro dessa análise: será apenas o ponto de partida para a observação de uma rede de outros atores que entram em cena e desempenham ações em torno da mediação de sentidos estabelecida no processo de midiatização a ser estudado.

\section{DISCUSSÃO: ASSOCIAÇÕES ENTRE ONU, ONG'S, EMPRESAS E ATIVISMO}

Após a contextualização teórico-metodológica dos fundamentos da TAR e sua possível associação ao campo da comunicação organizacional, apresenta-se o corpus de análise que foi mapeado. 0 mapeamento da cartografia de associações foi feito na primeira quinzena do mês de março de 2017, intervalo temporal marcado pela temática do feminismo pelo contexto do Dia Internacional da Mulher (08 de março). Esse período configura-se, assim, estratégico enquanto oportunidade de observar fenômenos de interação midiática entre diferentes organizações no ambiente digital, apropriando-se da temática para promover 0 engajamento com a causa da equidade de gênero em mensagens compartilhadas nos fluxos intermidiáticos.

Dada a natureza breve desse ensaio cartográfico, além do recorte temporal, escolheu-se enfocar o olhar sobre a associação entre organizações e atores, observada através do Facebook. Esse recorte se justifica, pois, além da sua intensa presença no cotidiano das pessoas, essa plataforma facilita para o pesquisador localizar associações entre atores diferentes pela sua forma de agenciamento sociotécnico: como a estrutura em feed, os perfis pessoais e fanpages e, de modo ainda mais importante, as possibilidades de marcações entre esses perfis e páginas tanto pelas organizações como pelo próprio público - o que cria uma rede se associações visíveis entre atores de múltipla natureza: empresas, ONGs, ativistas, celebridades, produtores de conteúdo e influenciadores digitais, trabalhadores de organizações, voluntários, políticos em seus perfis pessoais (às vezes geridos por assessoria de comunicação). Todo esse contexto favorece a observação de interações entre atores organizacionais e não-organizacionais em rede, justificando a escolha do Facebook como lugar prioritário de observação para se realizar uma cartografia das associações em fluxo, como vemos na montagem a seguir.

\section{ONU Mulheres Brasil \\ 7 de março às 18:15 . 6}

Rico Dalasam conta suas experiências na infância como menino negro e como isso formou seu espaço na sociedade.

\#ElesPorElas é um movimento para a igualdade de gênero e o empoderamento das mulheres, cujo objetivo é engajar homens e meninos para novas relaçöes de gênero sem atitudes e comportamentos machistas. No âmbito do movimento \#ElesPorElas (HeForShe), o documentário "Precisamos falar com os homens? Uma jornada pela igualdade de gênero" procurará aproximar os homens desse tema tão importante. O objetivo é mostrar que a igualdade de gênero é uma questão que afeta a todos e todas e que, portanto, é benéfica a homens e mulheres. Nele investigamos como se formam, se sustentam e de que modo podemos desconstruir os estereótipos de gênero nocivos, que perpetuam o nosso cenário atual. $O$ documentário é resultado de uma pesquisa qualitativa que rodou o Brasil e será complementado pela pesquisa quantitativa online ainda em curso.

A desigualdade de gênero é uma das violaçōes mais persistentes de direitos humanos do nosso tempo. Ainda que estejamos caminhando para uma realidade mais igualitária entre homens e mulheres, ainda há muito a se construir.

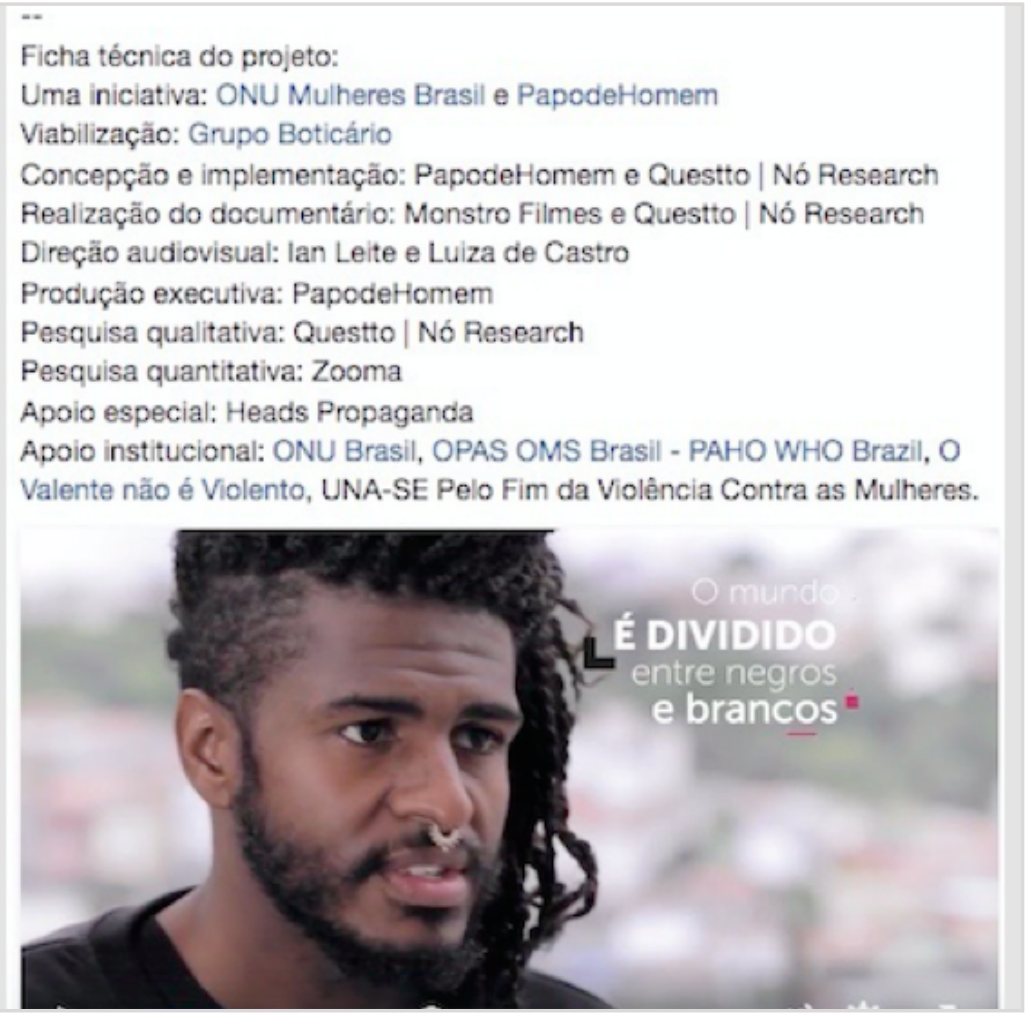

Ficha técnica do projeto:

Viabilização: Grupo Boticário

Nó Research

Pesquisa quantitativa: Zooma

Apoio especial: Heads Propaganda

(avio institucional: ONU Brasi, OPAS

Valente năo é Violento, UNA-SE Pelo Fim da Violôncia Contra as Mulheres.

Imagem 1: Montagem feita de impressões de tela de postagem da página ONU Mulheres Brasil, na véspera do Dia Internacional da Mulher, mostrando a configuração de associação entre atores múltiplos, como organizações, movimentos coletivos, empresas, produtores de conteúdo e perfis de ativistas 
Do que se torna visível na avaliação dessa imagem, podemos notar que uma ação - o documentário disponível no canal da ONU Mulheres no Youtube "Precisamos falar com os homens? Uma jornada pela igualdade de gênero" - torna-se o elo que revela a associação forte entre atores diversos, como o rapperRico Dalasam (conhecido como um dos poucos queer rappers brasileiros, ativista da causa LGBT), o site/blog Papo de Homem, o Grupo Boticário (que reúne as marcas O Boticário, Eudora, Quem disse Berenice e The Beauty Box), OPAS/OMS Brasil (Organização Pan-americana de Saúde) e ainda a iniciativa "O valente não é violento", todos atores que aparecem assinalados pela ferramenta de marcação do Facebook, possibilitando uma rede de interações ainda maior de cada um desses atores com outros atores em suas páginas/perfis. Durante o período observado, séries de postagens com a marcação de outros atores se desenrolaram, de forma similar a essa apresentada.

Seguindo esse movimento, a cartografia dasassociações feita a partir do caso da ONU Mulheres consistiunoacompanhamento de uma rede híbrida e complexa de cruzamento de atores, em séries de postagens na página do Facebook. É curioso observar que, na maioria das postagens feitas durante o período observado aparecem associações entre diversos atores, e em todas elas há um cruzamento híbrido e complexo entre ONU Mulheres Brasil, ONU Brasil, atores-ONGs, atores-empresas e atorespessoas (sejam elas colaboradores das ONGs, celebridades ou ativistas e influenciadores digitais).

A seguir, apresenta-se um quadro que sintetiza, no período de um mês (março de 2017), a totalidade de atores chamados à associação pela ONU Mulheres em suas postagens no Facebook, tomando conjuntos de postagens repetidas algumas vezes durante o período, articulando uma ação de agenciamento ator-rede.

\begin{tabular}{|c|c|c|c|c|c|}
\hline Ator & Ator & Ator & Ator & Ator & Ator \\
\hline & ONGs & $\begin{array}{c}\text { Ativista (pessoas/ } \\
\text { personalidades/ } \\
\text { políticos) }\end{array}$ & $\begin{array}{l}\text { Canal de mídia/ } \\
\text { Blogueiro/ } \\
\text { Influenciador/ } \\
\text { Produtor }\end{array}$ & Empresas & $\begin{array}{c}\text { Iniciativas } \\
\text { sociais/causas }\end{array}$ \\
\hline $\begin{array}{l}\text { Postagens: } \\
\text { Projeto Donas } \\
\text { da Rua }\end{array}$ & & & $\begin{array}{c}\text { Maurício de Sousa } \\
\text { Produções }\end{array}$ & $\begin{array}{c}\text { Avianca } \\
\text { (aviação civil) }\end{array}$ & $\begin{array}{c}\text { ElesPorElas } \\
\text { HeForShe Brasil }\end{array}$ \\
\hline $\begin{array}{c}\text { Postagens: } \\
\text { Campanha } \\
\text { de Doação de } \\
\text { Pontos Smiles }\end{array}$ & & $\begin{array}{l}\text { Kenia Dias (atriz } \\
\text { e ativista negra) } \\
\text { Érico Brás (ator } \\
\text { e ativista) }\end{array}$ & $\begin{array}{c}\text { Casal criador do } \\
\text { canal do Youtube } \\
\text { "Tá bom pra } \\
\text { você?", que recria } \\
\text { peças publicitárias } \\
\text { com protagonismo } \\
\text { de negros }\end{array}$ & $\begin{array}{c}\text { Smiles (programa } \\
\text { de milhagem } \\
\text { Gol Aviação) } \\
\text { Livelo (programa } \\
\text { de fidelização } \\
\text { Banco do Brasil } \\
\text { e Bradesco) }\end{array}$ & \\
\hline $\begin{array}{c}\text { Postagens: } \\
\text { documentário } \\
\text { "Precisamos falar } \\
\text { com os homens?" }\end{array}$ & $\begin{array}{c}\text { OPAS / OMS } \\
\text { (Organização } \\
\text { Pan-americana } \\
\text { de Saúde) }\end{array}$ & $\begin{array}{l}\text { Rico Dalasam } \\
\text { (rapper LGBT) }\end{array}$ & $\begin{array}{l}\text { Papo de Homem } \\
\text { (blogueiro) }\end{array}$ & $\begin{array}{l}\text { Papo de Homem } \\
\text { (blogueiro) } \\
\text { Grupo Boticário }\end{array}$ & $\begin{array}{l}\text { O valente não } \\
\text { é violento }\end{array}$ \\
\hline
\end{tabular}




\begin{tabular}{|c|c|c|c|c|c|}
\hline Ator & Ator & Ator & Ator & Ator & Ator \\
\hline $\begin{array}{l}\text { Postagem: vídeo } \\
\text { Planeta } 5050\end{array}$ & $\begin{array}{l}\text { ELAS (fundo de } \\
\text { investimento } \\
\text { social) }\end{array}$ & & Rede Globo & & \\
\hline $\begin{array}{c}\text { Postagens: } \\
\text { Década Afro } \\
\text { Mulheres Negras }\end{array}$ & & $\begin{array}{c}\text { Kenia Dias } \\
\text { Carol Lima } \\
\text { Xan Ravelli } \\
\text { Winnie Bueno } \\
\text { Patrícia Rammos }\end{array}$ & $\begin{array}{c}\text { Youtubers } \\
\text { negras Canal } \\
\text { "Já tinha Carol", } \\
\text { "Soul Vaidosa", } \\
\text { "Preta Expressa" } \\
\text { e "Um abadá } \\
\text { pra cada dia" }\end{array}$ & & \\
\hline
\end{tabular}

Quadro 1: Associações entre organizações e atores, feito a partir do mapeamento das postagens da página ONU Brasil durante o mês de março de 2017.

Nesse ponto, cabe retomar a argumentação de Kunsch (2003) para o conceito da comunicação organizacional, como campo que comporta 0 estudo do fenômeno comunicacional em organizações de qualquer natureza: pública, privada, sem fins lucrativos, ONGs, fundações, podendo contemplar estudos de todos tipos de organização.

Para além dessa dimensão, pretende-se, pela cartografia de associações apresentada neste artigo, apontar que o alargamento do conceito de comunicação organizacional passa pela dimensão de contemplar as relações públicas na própria riqueza da diversidade das organizações. Mas mais do que isso, como se propôs através da sociologia das associações entre organizações e outros atores, é interessante adotar o ponto de vista que se empenha em retirar as organizações do centro da rede de relações com públicos. Do ponto de vista das associações entre atores, todos envolvidos em torno da temática da igualdade de gênero, o que se consegue é enxergar uma relação, mediada pela comunicação, em que a organização é mais um entre outros atores, articulados em um fluxo de sentidos estabelecidos em rede. Assim, coloca-se um outro sentido de "público" para a dimensão do estudo organizacional: para além da dimensão dos públicos da organização numa perspectiva institucionalista, desenha-se uma esfera em que diversas associações convocam a ação coletiva, onde interesses são compartilhados e mesmo colocados em disputa, todo esse processo derivado da associação entre atores, preservados em sua diversidade.

Cabe ressaltar que durante esse período existiu a produção de postagens da ONU Mulheres enfocando a divulgação de conteúdos institucionais produzidos e colocados no site - canal institucional por natureza. 0 esforço analítico não se concentrou nesse tipo de postagem ou mesmo no conteúdo das postagens, já que a abordagem metodológica da cartografia não visa a um discurso da organização (e às relações dela com diversos stakeholders). De fato, o que pretendemos com o uso teórico-metodológico da TAR é exatamente propor outro modo de nos aproximar do estudo da comunicação no contexto da midiatização: entendendo a comunicação organizacional aqui em uma visada socioconstrutivista (tal como os estudiosos do campo se empenham em fazer através dos estudos da visão da organização a partir da teoria da complexidade), talvez a teoria ator-rede possa trazer uma nova ontologia do campo organizacional ao propor outro entendimento do que significa estudar a dimensão social, percebendo-a como conjunto de associações estabelecidas entre atores em rede. 


\section{CONSIDERAÇÕES FINAIS}

Para concluir, é importante destacar o modo como, ao cartografar associações entre esses atores, o quadro do mapeamento permite observar a formação de um atravessamento entre organizações de primeiro, segundo e terceiro setor, e ainda entre atores não-organizacionais. 0 modo como pessoas físicas - sejam elas celebridades e influenciadores, sejam elas portavozes da $\mathrm{ONU}$, ou colaboradores, ou ainda ativistas e influenciadores - se articulam em uma rede discursiva no fluxo das marcações do Facebook aponta para o imbricamento de dimensões várias como a política, a empresarial, a institucional, a do ativismo e engajamento cívico, todas convocadas em um contexto de difícil separação dessas fronteiras.

De fato, compreender a comunicação organizacional pela perspectiva da TAR talvez implique aceitar esse caráter híbrido, em que a dimensão política aparece atravessada pelo caráter midiático (da visibilidade construída em processos de midiatização) e institucional, com implicações de dimensões que parecem conflitantes, por vezes inconciliáveis, como a mercadológica e a ativista. Com aproximação de diferentes atores em interação, confundem-se ainda as dinâmicas de público e privado, o que pode ser visto pelo modo como tanto celebridades como ativistas são chamados a se associar a organizações, validando-se enquanto atores comunicacionais mais pelas suas trajetórias de vida do que por suas facetas midiáticas - o que pode ser visto pelas marcações públicas de seus perfis pessoais no Facebook.

A temática da igualdade de gênero, portanto, deixa de servista apenas sob o prisma do discurso institucional de uma organização intergovernamental e desliza para a dimensão da ação política de ONGs e ativistas, e ainda da organização intergovernamental de maior relevância global, com centenas de projetos na área em todo o mundo. Contempladas as diferentes dimensões de cada ator, podemos também falar do sentido outro que emerge a partir da interação entre eles, enquanto rede. Nas trocas, uma dimensão política que vem da atuação da ONU parece demonstrar que essa organização, empenhada em alcançar a meta da desigualdade de gênero, entende a visibilidade midiática e o engajamento da sociedade em processos de comunicação em rede como meios - função mediadora - para se facilitar a transformação da dinâmica social.

Ao mesmo tempo, o poder mercadológico de investimento de organizações com objetivos mercadológicos, como Smiles, Livelo e Grupo Boticário, parece catalizar a visibilidade para a temática, beneficiando a ONU e outras organizações, comunidades e/ ou ativistas associados em rede, no sentido da dispersão e circulação da mensagem de interesse e impacto social.

Talvez seja esse o sentido de complexificação que se deseja apontar no artigo: o campo da comunicação organizacional, ao congregar estudos de organizações de interesse público, privado, comunitário, e ainda 0 ativismo em atores nãoorganizacionais em associação, pode-se cartografar não apenas seus interesses compartilhados, mas ainda as disputas de sentido: um movimento que parece apontar para o deslocamento do próprio campo de estudos da comunicação organizacional, através do estudo de discursos midiatizados na web.

Tal como apresentado nesse artigo, há um vasto campo para a investigação sobre a formação de redes de associações entre organizações de interesse público e privado, que têm sido formadas com cada vez mais frequência, na dinâmica de fluxos intermidiáticos da comunicação digital. 0 que aqui se apresentou, de forma exploratória, pode ser aprimorado por análises mais aprofundadas para cartografar associações entre organizações em rede, com o objetivo de lançar um olhar mais amplo do que o institucionalista, buscando entender processos de midiatização em que atravessamentos discursivos trazem ao mesmo fluxo um jogo de intenções diversas - política, institucional e mesmo mercadológica. 
Assim, compreendendo uma possível sociologia das associações entre organizações a partir do olhar da teoria atorrede, poderíamos empreender estudos sobre os discursos das organizações enquanto atravessados de questões políticas e socioculturais relevantes, com base em uma lógica que busca superar binarismos e conciliar a tradição de estudos de midiatização com uma abordagem mais integrada à dinâmica social. A abordagem da TAR mostra-se, então, rica para a concepção epistemológica de processos de mediação híbridos, tais como o que se articulou no caso trazido da atuação da rede de organizações formada a partir do olhar sobre a ONU Mulheres, percorrendo fluxos institucionais e políticos que se cruzaram através da temática da igualdade de gênero.

\section{REFERÊNCIAS}

BALDISSERA, Rudimar. Comunicação organizacional: uma reflexão possível a partir do paradigma da complexidade. In: OLIVEIRA, Ivone de Lourdes; SOARES, Ana T. Nogueira (Orgs.). Interfaces e tendências da comunicação no contexto das organizações. São Caetano do Sul, SP: Difusão, 2008. P. 149-177.

Comunicação organizacional na perspectiva da complexidade. Organicom - Revista Brasileira de Comunicação Organizacional e Relações Públicas, São Paulo, ECA-USP, v. 6, n. 10/11, p. 115-120, 2011.

FAUSTO NETO, Antonio. Comunicação das organizações: da vigilância aos pontos de fuga. In: OLIVEIRA, Ivone de L.; SOARES, Ana T. Nogueira. Interfaces e tendências da comunicação no contexto das organizações. São Caetano do Sul, SP, Difusão, 2008. p. 39-63.

FRANÇA, Vera R. Veiga. Sujeitos da comunicação, sujeitos em comunicação. In: FRANÇA, Vera; GUIMARÃES, César (Orgs.). Na mídia, na rua: narrativas do cotidiano. Belo Horizonte: Autêntica, 2006. p. 61-88.

KUNSCH, Margarida M. Krohling. Planejamento de relações públicas na comunicação integrada. 4. ed. - rev., atual. e ampl. São Paulo: Summus, 2003.

LATOUR, Bruno. Reagregando o social: uma introdução à teoria do ator-rede. Salvador: Edufba, 2012.

LEMOS, André. Espaço, mídia locativa e teoria ator-rede. Galáxia - revista do Programa de Pós-Graduação em Comunicação e Semiótica, PUC-SP, n. 25, 2013.

LIMA, Fabia Pereira. Possíveis contribuições do paradigma relacional para o estudo da comunicação no contexto organizacional. In: OLIVEIRA, Ivone de Lourdes; SOARES, Ana T. Nogueira (Orgs.). Interfaces e tendências da comunicação no contexto das organizações. São Caetano do Sul, SP: Difusão, 2008. p. 109-127.

SANTAELLA, Lúcia. Temas e dilemas do pós-digital: a voz da política. São Paulo: Paulus, 2016.

Texto recebido em 10.04.2017 e aprovado em 05.06.2017. 